\title{
A PERFORMATIVIDADE NOS QUATRO DISCURSOS
}

Bianca Novaes de Mello

Doutora em Psicologia Clínica (PUC-Rio); Professora Adjunta da Universidade Federal Fluminense

(UFF/PUNF).

\section{Resumo}

Pretende-se demonstrar que a tese lacaniana segundo a qual o sujeito se constitui como efeito da cadeia significante baseia-se em uma noção de estrutura da linguagem que abarca a inscrição do sujeito em um laço social. Uma vez que a constituição do sujeito pela linguagem (S1-S2) produz um sujeito divido (\$) e um resíduo denominado objeto a (a), veremos que estes quatro termos se ordenam, compondo os quatro tipos de discurso. Para tanto, retoma-se as noções de alienação e separação, a fim de assinalar que o discurso do mestre pode ser extraído dessas operações e ser pensado como gesto constituinte de todo laço social. A fim de destacar o modo particular pelo qual Lacan elabora a noção de estrutura da linguagem nela incluindo a possibilidade de produção do sujeito e de inscrição em um laço social, aborda-se também a noção estruturalista de linguagem e a noção de performativo, oriunda da filosofia pragmática da linguagem.

Palavras-chave: sujeito, performativo, discursos.

\section{PERFORMATIVITY IN THE FOUR DISCOURSES}

\begin{abstract}
This paper intend to demonstrate that one of the consequences of the Lacan's thesis according which the subject is constituted as an effect of the significant chain is that the Lacanian notion of language structure encompasses the inscription of the subject in a social link. Once the constitution of the subject by the language (S1-S2) produces a divided subject $(\$)$ and a residual called object a (a), we'll see that this four terms are combined creating the four types discourse. In that way, the notions of alienation and separation are resumed, in order to emphasize that the discourse of the master can be extracted from these operations and be considered as the constitutive gesture of any social link. In order to reinforce that the Lacanian notion of structure of language encompasses the possibility of to produce a subject and the inscription in a social link, it is considered also the structuralist notion of language and the notion of performative formulated from the pragmatic philosophy of language.
\end{abstract}

Keywords: subject, performative, discourse. 


\title{
LA PERFORMATIVIDAD EN LOS CUATRO DISCURSOS
}

\begin{abstract}
Resumen
Se demuestra que la tesis Lacaniana según la cual el sujeto es constituido como efecto de la cadena significante encuentrase basada en una noción de estructura del lenguaje que abarca la inscripción del sujeto en un lazo social. Una vez que la constitución del sujeto por el lenguaje (S1-S2) produce un sujeto dividido (\$) y un residuo denominado objeto a (a), veremos que estos cuatro términos se ordenan componiendo los cuatro tipos de discurso. Para tanto, retomanse las nociones de alienación y separación de modo a señalar que el discurso del maestro puede ser extraído de esas operaciones y ser pensado como gesto constituiente del lazo social. Con el objetivo de destacar el modo particular por el cual Lacan elabora la noción de estuctura del lenguaje en ella incluyendo la posibilidad de producción del sujeto y inscripción en un lazo social, se considera también la noción estructuralista del lenguaje y la noción de performativo encontrada en la filosofia pragmatica del lenguaje.
\end{abstract}

Palabras clave: sujeto, performatividad, discurso.

\section{INTRODUÇÃO}

O ensino de Lacan é marcado pela ideia de que a experiência psicanalítica e os conceitos formulados a partir dela só podem ser devidamente compreendidos através do campo da linguagem. O modelo de linguagem a que Lacan faz referência, durante grande parte de sua obra, é a linguística de Saussure e Jakobson. Contudo, uma vez que seu interesse não se dirige diretamente à linguagem, mas à constituição do sujeito do inconsciente pela linguagem, Lacan acaba por modificar as noções tomadas à linguística estrutural.

Não reconhecer as profundas modificações que Lacan imprimiu no uso de noções advindas da linguística estrutural poderia levar-nos a incorrer no equívoco de dirigir à psicanálise lacaniana à mesma crítica que os pósestruturalistas proferiram contra as diversas vertentes do estruturalismo. Segundo Dosse (1993), os pós-estruturalistas consideraram que o estruturalismo culminava inevitavelmente em um formalismo exacerbado no qual não há lugar para o sujeito. Esta conhecida crítica ao estruturalismo atribui a esta corrente ter executado "a morte do sujeito", dado o privilégio concedido ao caráter formal da língua em detrimento da individualidade do falante, de sua história e de seu contexto social. No entanto, o que Lacan faz é tomar a noção estruturalista de significante para conceber, justamente, o sujeito: efeito da cadeia significante.

Certamente, essa empreitada de Lacan não se efetua sem que a própria noção de significante seja modificada. Na linguística saussuriana, o significante é definido como uma "imagem acústica" que é unida arbitrariamente a um "conceito" ou "significado", formando o signo linguístico. São os signos que em 
relação com outros signos produzem o sentido ou o "valor" do signo, constituindo o sistema da língua (Saussurre, 1915/2006). Para Lacan, o significante é aquilo que representa o sujeito para outro significante. Um significante especial, chamado de "significante-mestre" (S1), vem representar o sujeito para outros significantes (S2). É assim que o par S1-S2, concebido como cadeia significante, produz o sujeito como seu efeito. Desta tese lacaniana, Zizek (2005) oferece a seguinte ilustração: um homem está em um hospital, sob seu leito consta o prontuário com suas informações, tais como temperatura, pressão, medicamentos administrados, etc. Esse prontuário seria como um S1, ele representa o sujeito para o saber médico, para o conjunto dos outros significantes (S2) para os quais o sujeito é representado - desde que esse S1 se insira neste conjunto, formando a cadeia de sentido, S1-S2. O que é o sujeito? É uma substância, um homem dotado de subjetividade, um ser? Não, ele é um efeito da cadeia significante. Contudo, antes que reduzir o sujeito a um efeito dos elementos do sistema da língua, ou seja, ao significante saussuriano que é apenas uma "imagem acústica", Lacan traz à cena um significante especial: o significante-mestre, que é também um imperativo, pois exerce a função de um mandato simbólico. Um mandato simbólico a partir do qual o sujeito se constituiria, buscando uma identidade para o seu ser, que, por sua vez, falha em se realizar plenamente, pois essa cadeia significante que o produz não opera como um sistema fechado, tal como Saussure concebe o sistema da língua.

Se a representação que o significante-mestre oferece ao sujeito para os outros significantes fosse unívoca, o sujeito seria inteiramente identificável ao significante-mestre. Portanto, seria mero efeito do significante. Mas o que Lacan (1964/1985) demonstra no Seminário 11, ao abordar a constituição do sujeito pela estrutura da linguagem, é que o sujeito não é apenas efeito do significante, é efeito também de um resíduo da cadeia significante, chamado por ele de objeto a - um resto produzido pela cadeia significante e inassimilável por ela. Por isso Lacan (1964/1985) elabora duas operações dialéticas através das quais o sujeito se constitui pela estrutura da linguagem: a alienação e a separação. A alienação vem demonstrar que esse significante-mestre que representa o sujeito não o representa de forma integral, emergindo dessa operação uma primeira falta. E a separação vem demonstrar que o sujeito situa em termos de desejo a interrogação dessa não representatividade integral do significante, extraindo dessa ausência de resposta uma satisfação pulsional ou gozo. O objeto a, 
concebido como o objeto dessa estranha satisfação, é introduzido nessa operação através da qual o sujeito se constitui pela cadeia significante. Esta cadeia (S1-S2), ao constituir o sujeito, produz um excedente, algo não abarcado pelo o que Lacan denomina como campo do grande Outro: "o lugar em que se situa a cadeia do significante que comanda tudo que vai poder presentificar-se do sujeito (...)" (Lacan, 1964/1985, p.193).

Laurent (1997) fornece o exemplo do rapaz identificado ao significantemestre "menino mau". Esse significante norteará a vida do sujeito. Mas acontece que o rapaz não é somente um "menino mau", ele é também outras coisas, pois, uma vez que esse significante se insere na cadeia, surgem significações decorrentes do deslizamento significante. Portanto, da alienação emerge uma primeira falta: a de que o sujeito não é inteiramente representável pelo Outro. E da separação emerge uma outra falta. Uma falta de resposta do Outro em termos de desejo - como se o sujeito passasse a perguntar ao grande Outro o que este deseja dele ao lhe atribuir um significante que não o representa integralmente. Dessa ausência mesma de resposta, o sujeito extrairá um modo particular de gozo ao redor desse resíduo denominado objeto a - objeto de uma satisfação pulsional. Ora, a noção de estrutura cunhada pelo estruturalismo, extraída da noção de sistema da língua formulada por Saussure, é concebida como um sistema fechado regido por leis que lhe são imanentes: as leis que regem o sistema da língua. Seriam as operações de alienação e separação redutível a um tal sistema? De acordo com Dosse (1993), uma estrutura é um sistema fechado que possui um modo de funcionamento interno, independente do que the é exterior. Os seus termos são definidos uns em relação aos outros, formando um sistema que possui leis universais próprias que regem 0 funcionamento de seus elementos. Em uma estrutura não há lugar para um resto - todo produto é dedutível da estrutura e por ela assimilado. Portanto, essa noção de estrutura, ao ser pensada por Lacan como constituinte do sujeito, é por ele reformulada ao nela inserir esse elemento produzido e irredutível a ela, o objeto a. Conforme destaca Zupancic: "Se o estruturalismo realmente identifica o sujeito com a estrutura (O Outro), Lacan intervém (...): ele introduz o sujeito como um correlato da falta no Outro; ou seja, como correlato do ponto onde a estrutura falha em fechar-se totalmente" (Zupancic, 2000, p. 29).

Pretende-se demonstrar neste artigo que uma das consequências deste modo de conceber a constituição do sujeito pela linguagem é que a noção de 
estrutura da linguagem concebida por Lacan abarca a inserção do sujeito em um laço social. Uma vez que a entrada do sujeito na e pela linguagem (S1-S2) produz um sujeito incompleto, cindido (\$), e um resíduo denominado objeto a, veremos que estes quatro termos se ordenam, constituindo quatro tipos de modalidades de laço social. Em outras palavras, o sujeito extrai um gozo do fato de ser constituído através da representação, mesmo não integral, que um significante dá dele a outro significante, e por meio dos modos de gozo ele se relacionará com o Outro. O que Lacan chama de discursos são os modos pelos quais advém um gozo da inserção do sujeito no campo do Outro, engendrando vínculo social.

Se, em 1964, Lacan buscava responder à crítica segundo a qual a incidência do estruturalismo em sua abordagem da psicanálise havia negligenciado a dimensão pulsional, em 1969, se empenhará em demonstrar que sua abordagem abrange questões de alçada social. Lacan, em "O Seminário 17 - O avesso da psicanálise" (1969-1970/1992), replica à provocação do movimento estudantil de 1968, grafada nas paredes de Paris: "As estruturas não vão às ruas". A fim de responder a essa crítica, Lacan (1969-1970/1992) demonstra que seu ensino pode dar conta dos acontecimentos sociais e revela a mudança discursiva que se operava em maio de 68. Ao mesmo tempo em que se contrapunha à ideia de que a noção de estrutura era incapaz de atingir os eventos da vida social, denunciava que o discurso universitário, mascarado sob a forma de um saber neutro, imparcial e válido para todos, oculta que se ampara em uma posição de mestria e dominação. Segundo Zizek (2005):

Nesse seminário, Lacan se esforça por demonstrar que as estruturas caminham sim pelas ruas, ou seja, que os arranjos estruturais podem explicar irrupções sociais, como as de 1968. Em lugar de um Outro simbólico com seu conjunto de regras a priori que garantiriam a coesão social, temos a matriz de passagens de um discurso a outro: o interesse de Lacan está focalizado na passagem do discurso do mestre ao discurso da universidade como discurso hegemônico na sociedade contemporânea. (Zizek, 2005, p.105)

No Seminário 17, como decorrência da fórmula extraída das operações de alienação e separação, Lacan elabora as modalidades de discurso, que consistem em vínculos sociais, abarcando, portanto, a dimensão social que os opositores do estruturalismo julgavam inapreensível pela estrutura. Ora, Lacan apreende essa dimensão apenas em virtude da ruptura/apropriação empreendida no Seminário 11. Afinal, de que fórmula Lacan extrai os discursos? Ele responde: 
Assim é a fórmula. Que diz ela? Ela situa um momento. (...) Ela diz que é no instante mesmo em que o S1 intervém no campo já constituído dos outros significantes, na medida em que eles já se articulam entre si como tais, que ao intervir junto a um outro, do sistema, surge isto, \$, que é o que chamamos de sujeito como dividido. (...) Enfim, nós sempre acentuamos que desse trajeto surge alguma coisa definida como uma perda. É isto o que designa a letra que se lê como sendo o objeto a. (Lacan, 1969-1970/1992, p.13)

Conforme assinala Zizek (2005), "os quatro discursos de Lacan, que articulam as quatro posições subjetivas dentro de um laço social discursivo, derivam logicamente da fórmula do significante" (Zizek, 2005, p.107). Lacan retoma a dinâmica da alienação e separação, segundo a qual um significantemestre (S1) representa um sujeito (\$) para outro significante (S2), produzindo um resto, denominado objeto a (a). São esses quatro elementos que comporão o matema dos quatro discursos, com a ressalva, feita por Lacan na primeira lição do Seminário 17, de que o S2 não designa apenas um significante, mas a bateria significante, já articulada de algum modo, como um saber. E o S1 designa propriamente apenas um significante, aquele que intervém na bateria significante, ou seja, no campo de saber. Em suas palavras, Lacan assim retifica a forma fundamental pela qual o sujeito advém da "estrutura":

Mas, simplificando, consideramos S1 e, designada pelo signo S2, a bateria dos significantes. Trata-se daqueles que já estão ali, ao passo que no ponto de origem em que nos colocamos para fixar o que vem a ser o discurso, o discurso concebido como estatuto do enunciado, S1 é aquele que deve ser visto como interveniente. Ele intervém numa bateria significante que não temos direito algum, jamais, de considerar dispersa, de considerar que já não integra a rede do que se chama um saber. (Lacan, 1969-1970/1992, p.11)

\section{O Caráter Performativo do Significante-mestre}

As quatro modalidades discursivas são as quatro formas possíveis de se fazer vínculo social. Através da linguagem, relações fundamentais e estáveis no campo do gozo são instauradas, a partir de uma série de enunciados primordiais que determinam uma modalidade de laço social específica. Lacan diz tratar-se de "um discurso sem palavras": "Pois não há necessidade destas [as palavras] para que nossa conduta, nossos atos, eventualmente, se inscrevam no âmbito de certos enunciados primordiais" (Lacan, 1969-1970/1992, p. 11). Mas acrescenta que, apesar de serem "discursos sem palavras", não podem manter-se sem a linguagem. 
Dependem da linguagem porque são maneiras de lidar com o resto produzido pela constituição do sujeito pela linguagem. Além disso, Lacan (1973/2003) destaca que o discurso é da ordem de um dizer. Um dizer, diferentemente de um dito, funda fatos, laços sociais entre os sujeitos. Portanto, o discurso é um ato, como tal é inseparável da instituição da ordem significante, uma vez que não há ato fora do contexto instaurado pela lei simbólica. Conforme Lacan (1969-1970/1992) assinala: "Não poderia haver ato fora de um campo já tão completamente articulado que aí a lei não tivesse seu lugar. Não há outro ato a não ser $o$ ato que se refere aos efeitos dessa articulação significante e que comporta toda a sua problemática (...)" (Lacan, 1969-1970/1992, p.118).

O discurso como ato, por ser inseparável de uma referência a um mandato simbólico, articula assim a dimensão significante à dimensão de uma prática inscrita em laços sociais. Ao definir o discurso como "vínculo social", Lacan utiliza a mesma expressão com que Austin caracteriza os atos de fala, e, com isso, introduz na dimensão da linguagem algo que é da ordem de uma pragmática (Rudge, 1998).

A dimensão pragmática da linguagem, segundo Marcondes (2005), compõe uma das três áreas nas quais a linguagem é tradicionalmente dividida: a sintaxe, que analisa a relação entre os signos; a semântica, que examina a relação dos signos com os objetos a que se referem, e a pragmática que "diz respeito à relação dos signos com seus usuários e como estes interpretam e os empregam" (Marcondes, 2005, p.8). A valorização da dimensão pragmática da linguagem aparece na teoria dos atos de fala de Austin como uma reação à filosofia analítica da linguagem, que, segundo Recanati (1970), considerava a linguagem natural, ou seja, a linguagem que usamos no dia a dia, a partir do modelo da linguagem artificial da lógica. Por meio de uma notação lógica, chegava-se ao "sentido" dos enunciados. Para a filosofia analítica da linguagem, a estrutura lógica dos enunciados as dota de um sentido passível de ser submetido ao critério de verdade. Se um enunciado é verdadeiro, ele corresponde às coisas na realidade. Já a filosofia pragmática da linguagem, ou filosofia da linguagem ordinária, vem, em contrapartida, se debruçar sobre enunciados que pareciam desprovidos de sentido para a lógica formal. É assim que Austin é levado a elaborar uma teoria da linguagem como ação em um contexto a partir da formulação da noção de enunciados denominados por ele como "performativos", revelando sua dimensão pragmática. 
Em uma série de conferências proferidas por Austin em 1953, publicadas sob o título de How to do things with words (Como fazer coisas com palavras), traduzidas na versão brasileira como "Quando dizer é fazer - palavras e ações" (1953/1990), a teoria dos atos de fala é apresentada inicialmente através da distinção entre proferimentos performativos e proferimentos constatativos. Os proferimentos constativos são aqueles que podem ser sujeitos à verdade e falsidade pela adequação de seus enunciados à realidade, como "O copo está sobre a mesa". Os proferimentos perfomativos se referem a proposições que, ao invés de corresponderem a algo na realidade, inauguram um estado de coisas; proferimentos tais como "Prometo", "Desculpe", "Batizo esse navio de ...", "A sessão está aberta", dentre outros. São proferimentos que realizam uma ação em um contexto social. Tais proferimentos não são suscetíveis de verdade ou falsidade, mas à felicidade ou infelicidade do ato, ou seja, o critério é se o ato se realiza ou não. Um exemplo de enunciado performático pode ser dado por: "A sessão está aberta". Este enunciado não pode ser avaliado por um critério de verdade ou falsidade, somente podemos avaliá-lo quanto a seu sucesso, ou seja, se a sessão se iniciará ou não. E para que ele seja bem sucedido é necessária a atuação de diversos fatores que não estão presentes no sistema das regras da língua, embora necessitem deles. Para que a intenção seja alcançada é preciso que quem enuncie esteja no lugar adequado, seja investido de autoridade para enunciar tal proposição, esteja vestindo uma toga, e, ainda, é necessário que quem esteja presente na sessão reconheça o poder naquele que profere 0 enunciado, etc. Assim, o que determina a felicidade de um enunciado performático são fatores contextuais, sociais. Para definir os critérios que garantem a felicidade ou não do ato, Austin constrói uma "doutrina das infelicidades", estabelecendo as circunstâncias que devem estar presente no contexto social para que o ato de fala seja feliz. Segundo Austin (1953/1990):

Genericamente falando, é sempre necessário que as circunstâncias em que as palavras forem proferidas sejam, de algum modo, apropriadas; frequentemente é necessário que o próprio falante, ou outras pessoas, também realize determinadas ações de certo tipo, quer sejam ações "físicas" ou "mentais". (Austin, 1953/1990, p.26)

A linguagem é, portanto, concebida como possuidora de um aspecto pragmático, uma vez que os performativos são ações em um contexto social. E é essa mesma dimensão da linguagem que vem se apresentar na noção lacaniana 
de discurso como laço social. Há algo na linguagem que faz com que sujeito constituído por ela se insira em um laço social.

Posteriormente, ao longo das palestras publicadas no livro aqui citado, Austin estende sua teoria dos atos de fala, ao abandonar a distinção entre constatativo e performativo. Ele conclui que não apenas proferimentos tais como prometer, batizar, desculpar e outros, realizam ações em um contexto. Proferimentos declarativos, constativos ou descritivos também realizam ações no mundo. Quando profiro um constativo tal como "Esta caneta é azul", realizo a ação de afirmar. Assim, Austin reformula sua teoria, propondo que qualquer proferimento deve ser compreendido a partir de três aspectos que compõem todo proferimento: locutório, ilocutório e perlocutório.

Todo proferimento é um ato de fala porque é composto de três atos simultâneos: um ato locucionário, que produz tanto os sons pertencentes a um vocabulário quanto a articulação entre a sintaxe e a semântica, lugar em que se dá a significação no sentido tradicional; um ato ilocucionário, que é o ato de realização de uma ação através de um enunciado, por exemplo, "o ato de promessa", que pode ser realizado por um enunciado que se inicie por "eu prometo...," ou por simplesmente "eu irei lhe dar..."; por último, um ato perlocucionário, que é o ato que produz efeitos sobre o interlocutor. O caráter de convenção social da linguagem e de ação nesse contexto continua resguardado nesta reformulação da teoria dos atos de fala, pois a força ilocucionária é sempre convencionada socialmente (por exemplo, prometer, declarar, afirmar ou asserir, ordenar, etc.) e é uma ação empreendida em contexto social; embora o aspecto perlocucionário não o seja. Em suas palavras: "Atos ilocucionários são atos convencionais; atos perlocucionários não são convencionais. (...) embora se possam utilizar atos convencionais para produzir o ato perlocucionário" (Austin, 1990, p.104). Afinal, nada garante que uma pessoa que profira uma ordem seja obedecida, pois para que haja sucesso em seu imperativo é necessária a ação da pessoa que é ordenada, a que sofre os efeitos do ilocucionário.

Essa função fundamental que o contexto ocupa insere sua abordagem da linguagem na dimensão social. Mas ao supor que existem convenções sociais que regem, seja o performativa em sua primeira teoria; seja o ato ilocucionário na segunda, Austin supõe um contexto unívoco. O contexto social ocupa aqui o lugar de um grande Outro completo, um simbólico que dá garantias e respostas ao sujeito, distinguindo-se, portanto, da noção lacaniana de simbólico. Sob a 
perspectiva lacaniana, a inscrição da linguagem em um laço social se efetua em virtude da inconsistência simbólica mesma, como se pode observar nos quatro discursos. Ainda que o mandato simbólico, sob a forma de um significantemestre, não se realize de forma integral, pois, como vimos, ele não oferece ao sujeito uma significação para seu ser, dado que não o representa integralmente; ainda assim possui o caráter de um performativo, uma vez que visa instaurar um estado de coisas.

Essa dimensão performativa do significante-mestre é abordada por Zizek (1991) através da noção de "performativo puro" elaborada por Searle, um filósofo da linguagem pertencente como Austin à Escola de Oxford, mas que tece uma crítica à noção austiniana de performativo, nela integrando também a segunda teoria dos atos de fala de Austin. Searle reduz a noção de constatativo da teoria inicial de Austin aos enunciados que, na segunda teoria de Austin, são classificados como possuindo a força ilocucionária de uma afirmação, as assertivas. E o performativo é reduzido aos enunciados que na segunda teoria possuem a força ilocucionária de uma ordem, os imperativos. A partir dessa intersecção dos dois momentos da teoria dos atos de fala de Austin, Searle considera que há um tipo de performativo, as declarações, que são, ao mesmo tempo, constatativo (ou assertivas) e perfomativo (ou imperativos); e as denomina como performativo puro.

De acordo com o ponto de vista de Searle, o constatativo, ao buscar verificar a correspondência do enunciado ao estado de coisas na realidade, parte das palavras para o mundo, enquanto o performativo, ao instaurar um estado de coisas, parte do mundo para as palavras. As declarações, por sua vez, realizam esses dois atos simultaneamente, pois, para Searle, as declarações somente instauram um estado de coisas, constatando, ao mesmo tempo, esse mesmo estado de coisas. Zizek (1991) oferece a seguinte ilustração desta tese de Searle:

$$
\begin{aligned}
& \text { Tomemos o enunciado "A sessão está suspensa": que realiza o } \\
& \text { locutor ao pronunciar essa frase? Instaura um novo estado de coisas } \\
& \text { no mundo (o fato de a sessão estar suspensa), e, portanto, a direção } \\
& \text { vai do mundo para as palavras. E como o instaura? Apresentando } \\
& \text { esse estado, através de seu enunciado, como já consumado: ele } \\
& \text { constata que a sessão está suspensa - realiza o ato ao descrevê-lo } \\
& \text { como realizado (Zizek, 1991, p. 221). }
\end{aligned}
$$

Se tomarmos como exemplo, o significante-mestre "nazismo", também já ilustrado por Zizek, podemos entender que esse significante visa unificar a 
Alemanha pela exterminação das raças inferiores, justamente afirmando que a nação alemã se constitui pela raça ariana. Que o significante-mestre fracasse em realizar seu mandato simbólico e ainda assim, desse fracasso mesmo, o sujeito extraia um gozo inserindo-se um em um laço social é o que os discursos demonstram. E veremos como esse impossível performativo puro se situa em cada um dos quatro discursos.

\section{O Performativo Puro nos Quatro Discursos}

Se retomamos a constituição do sujeito pelo significante, o ponto de partida dos quatro discursos é o discurso do mestre, que situa o significante-mestre no lugar de agente. No lugar de agente, o significante-mestre coincide com o mandato simbólico que instaura, ocultando, no lugar da verdade, a divisão subjetiva tributária da inconsistência simbólica. Dirigido a um campo de saber, ou seja, a um campo de significantes que ele supõe dispersos e se encarrega de unificá-los, o mestre produz uma região que será rejeitada e excluída de seu alcance (a), a pretexto de realizar integralmente o mandato simbólico. É o caso, exemplificado por Zizek (1992, 2005) várias vezes, da irrupção do nazismo na Alemanha. Buscando unificar a Alemanha em situação de crise, surge o significante-mestre nazismo, impondo um mandato simbólico, a fim de ocultar, no lugar da verdade, a divisão da sociedade alemã. Para que a Alemanha seja unificada, é necessário, no entanto, a produção de algo que deve ser excluído dessa sociedade, a saber, o judeu, como dejeto que ao ser eliminado permitiria a constituição da nação alemã. O mestre, situado no lugar de agente, jamais questiona seu mandato, nunca se interroga acerca da legitimidade de seu ato como podemos ver no filme "A queda. As últimas horas de Hitler", de Oliver Hirschbiegel, em que Hitler é apresentado como detentor de uma certeza inabalável, quando, mesmo no momento em que Berlim é invadida, jamais hesita quanto a seu fim, nem duvida do poder de seu exército. Conforme destaca Zizek (2005):

A ilusão do gesto do mestre é a coincidência completa entre o nível da enunciação (a posição subjetiva a partir da qual estou falando) e o nível do conteúdo enunciado, o que quer dizer que o que caracteriza o mestre é um ato de fala que me absorve totalmente, no qual "sou o que digo", em suma, um performativo plenamente realizado, autônomo. (Zizek, 2005, p.108) 
Essas posições que os quatro termos da constituição do sujeito pelo significante ocupam nos discursos são formuladas por Lacan em Radiofonia (1970/2003, p.447) do seguinte modo:

$$
\frac{\text { o agente }}{\text { a verdade }} \quad \frac{\text { o outro }}{\text { a produção }}
$$

Os lugares do discurso são fixos, o que distingue um discurso de outro são os termos que os ocupam: "S1", significante-mestre que desempenha a função de mandato simbólico do Outro; "S2", significante do saber, encarregado de dar consistência ao significante-mestre; "\$", sujeito dividido por se situar no intervalo significante, como um efeito de significação sempre provisório e evanescente, uma vez que o significante (S2) que viria dar um sentido para o significante que o representa (S1) acaba por ressignificá-lo indefinidamente; e "objeto a", resíduo de gozo desta operação e encarnação da inconsistência simbólica, funcionando como causa do desejo, por se oferecer como objeto de uma satisfação pulsional. As diferentes ocupações desses lugares fixos, através de um quarto de giro, definem as quatro modalidades de discurso: o discurso do mestre, o discurso da histérica, o discurso universitário e o discurso do analista.

O matema do discurso do mestre, matriz dos outros discursos por instaurar o laço fundamental de constituição do sujeito, pois "o gesto do mestre é o gesto fundacional de todo laço social" (Zizek, 2005, p.111), é assim formulado por Lacan (1969-1970/1992):

$$
\frac{S 1}{\$} \leftarrow \frac{S 2}{a}
$$

O discurso da histérica, por sua vez, é assim designado por Lacan (19691970/1992):

$$
\frac{\$}{a} \leftarrow \frac{\mathrm{S} 1}{\mathrm{~S} 2}
$$

Esse discurso, no lugar de agente, situa o sujeito dividido, assumido pela histérica, que endereça ao significante-mestre a demanda por uma resposta para sua divisão, apontando, ao mesmo tempo, a inconsistência do mandato simbólico. O que ela produz, ao dirigir sua demanda ao mestre, é um saber, um conjunto de significantes, que poderia vir a dar algum sentido para a questão de 
seu ser. No lugar da verdade, subjaz o gozo obtido pela histérica ao dirigir sua demanda ao Outro. Como no caso, ilustrado por Laurent (1997), do rapazinho identificado ao significante-mestre "menino mau". Ele não sabe o que é ser um menino mau para o Outro, e, por isso, encarna a pergunta da histérica ao mestre: "por que sou o que você diz que sou?". No gesto mesmo em que dirige essa pergunta ao Outro, supondo que ele possa respondê-la, a histérica assinala a inconsistência simbólica. O discurso da histérica, portanto, questiona a legitimidade e a eficácia do mandato simbólico, apontando a impossibilidade de um performativo puro. De acordo com Zizek (1992):

Essa pergunta emerge como uma reação do sujeito ao que Lacan, no início da década de 1950, chamava a "fala fundadora", o ato de conferir uma missão simbólica, o ato que, ao me nomear, define, estabelece meu lugar na rede simbólica: "És meu Mestre" (minha Mulher, meu Rei etc.). A propósito da "fala fundadora", a pergunta formulada é sempre: "O que, em mim, me faz ser o Mestre (a Mulher, o Rei etc.)?" (Zizek, 1992, p.173)

Já o discurso universitário é assim designado por Lacan (1969-1970/2003):

$$
\frac{\mathrm{S} 2}{\mathrm{~S} 1} \leftarrow \frac{\mathrm{a}}{\$}
$$

O discurso universitário, por sua vez, parte do saber no lugar de agente. O saber se dirige ao "a", ou seja, ao irredutível à rede simbólica, como uma tentativa de objetivar o que se apresenta como inapreensível pelo significante. Por exemplo, conforme indica Zizek (2005), no modelo pedagógico conservador, os representantes do saber se dirigem ao estudante, considerado como matéria bruta inassimilável, a qual convém incutir um saber neutro, imparcial e universal. O resultado produzido é um sujeito dividido, de plena posse de saberes, informações e teorias, mas completamente incapaz de servir-se delas para se orientar na vida, bem como orientar a dos demais. O que se oculta, no lugar da verdade, é que esse saber é sustentado por uma opinião particular, sacramentada pela academia e tornada palavra de ordem. O discurso da universidade desconhece, portanto, que seu pretenso saber neutro se ampara em uma postura de mestria. Nos termos da filosofia da linguagem ordinária de Austin, podemos dizer que o discurso da universidade ignora que seu enunciado supostamente constatativo se sustenta em um enunciado performativo. Ou ainda, segundo a visão de Searle, oculta que se sustenta na intencionalidade em um performativo puro. Conforme destaca Zizek (2005): 
A "verdade" do discurso da universidade, oculta atrás da barra, é o poder, ou seja, o significante-mestre: a mentira constitutiva do discurso universitário é que recusa sua dimensão performativa, apresentando o que efetivamente equivale a uma posição política baseada no poder como simples percepção do estado fático das coisas. (Zizek, 2005, p.113)

Enfim, o discurso do analista é assim designado por Lacan (19691970/2003):

$$
\frac{a}{S 2} \leftarrow \frac{\$}{S 1}
$$

O discurso do analista se dirige ao sujeito dividido, ou seja, àquele que demanda uma significação para seu ser, que se queixa da inconsistência simbólica. Mas, ao invés de responder à demanda do sujeito, ele encarna a impossibilidade mesma de seu pedido, porque, no lugar de agente, o analista ocupa a posição de objeto a e no lugar da verdade se sustenta no saber inconsciente. Diferentemente do discurso universitário, o saber que ocupa o lugar da verdade no discurso do analista não se refere a um saber neutro e universal. Se levarmos em consideração a definição que Lacan (19691970/1992) fornece de saber - como a bateria significante na qual os significantes estão de algum modo minimamente articulados- não seria abusivo depreender daí que o saber no qual o discurso do analista se sustenta diz respeito ao saber do inconsciente, da cadeia de significantes, que jamais oferece um sentido último. O saber consiste naqueles significantes que fracassam em dar consistência ao significante-mestre como mandato simbólico. Portanto, o discurso do analista, antes que oferecer um saber positivo e objetivável sobre o inconsciente, encerra, como verdade, a inconsistência simbólica da bateria significante, encarnada pelo analista, no lugar de agente. Desse lugar de agente, o objeto a encarna a própria inconsistência simbólica da qual o sujeito padece em sua pressuposição de que seria possível supri-la. Por ocupar assim esse lugar, antes que conceder uma interpretação que viesse preencher a busca de sentido a que o sujeito dividido se entrega, o analista opera meramente sobre a sua fala (endereçada e composta de significantes). Da fala do sujeito, o analista não destaca o sentido que lhe é demandado, mas tão somente seus significantes-mestres, ou seja, o próprio performativo. De acordo com Zizek (1991), o discurso do analista é o avesso do discurso do mestre, pois o lugar do agente é ocupado justamente pelo elemento mais irredutível ao performativo 
puro, o objeto a. Em suas palavras: "O discurso analítico nos livra do curtocircuito ilusório que é próprio do gesto performativo do Senhor [mestre], isola o S1 e permite vê-lo em sua verdadeira natureza, vazia, formal, tautológica, autoreferente: em suma, estúpida" (Zizek, 1991, p.220).

Portanto, vimos que, para Lacan, a função de um mandato simbólico possui a intencionalidade de um perfomativo, visando inaugurar um estado de coisas, uma vez que o significante-mestre pretende instaurar o mandato do Outro. Que essa função não se efetue de forma bem-sucedida, dada a inconsistência do simbólico, isso não significa que a dimensão performativa seja excluída da incidência da linguagem no inconsciente. Em todos os quatro discursos ela se manifesta. No da histérica, a dimensão performativa do significante-mestre é questionada. No universitário, ela é oculta como o que sustenta, no lugar da verdade, o próprio saber. No do analista, a dimensão performativa do significante-mestre é isolada da cadeia significante. Somente no discurso do mestre ela coincide com seu agente, sendo plenamente assumida como um performativo puro, embora mal sucedido.

\section{REFERÊNCIAS}

Austin, J. L. (1990). Quando dizer é fazer - palavras e ações. Porto Alegre: Artes Médicas.

Dosse, F. (1993). História do Estruturalismo. v. 1. São Paulo: Ensaio.

Lacan, J. (1985). O Seminário - livro 11 - Os quatro conceitos fundamentais da psicanálise. Rio de Janeiro: Zahar. (Original publicado em 1964).

Lacan, J. (1992). O Seminário: livro 17 - O avesso da psicanálise. Rio de Janeiro: Zahar. (Original publicado em 1969-1970).

Lacan, J. (2003). Radiofonia. In: Outros Escritos. Rio de Janeiro: Zahar. (Original publicado em 1970).

Lacan, J. (2003). O aturdito. In: Outros Escritos. Rio de Janeiro: Zahar. (Original publicado em 1973).

Laurent, E. (1997). Alienação e Separação I. In: Feldstein, R., Fink, B. \& Jaanus, M. (Orgs.), Para ler o Seminário 11 de Lacan. Rio de Janeiro: Zahar.

Marcondes, D. (2005). A pragmática na filosofia contemporânea. Rio de Janeiro: Zahar. 
Récanati, F. (1970). Du positivisme logique à là philosophie du langage ordinaire: naissance de la pragmatique In Austin, J. L. (Org.), Quand Dire c'est faire. Paris: Seuil.

Rudge, A. M. (1998). Pulsão e Linguagem - esboço de uma concepção psicanalítica do ato. Rio de Janeiro.

Saussure, F. (2006). Curso de Linguística Geral. São Paulo: Cultrix.

Zizek, S. (1991). O mais sublime dos histéricos - Hegel com Lacan. Rio de Janeiro: Zahar.

Zizek, S. (1992). Eles não sabem o que fazem - O sublime objeto da ideologia. Rio de Janeiro: Zahar.

Zizek, S. (2005). Violencia en acto. Buenos Aires: Paidós.

Zupancic, A. (2000). Ethics of the real - Kant, Lacan. London/ New York: Verso.

Contato: biancanovaes@id.uff.br

Recebido em: 23/04/2011

Revisado em: 18/05/2011

Aceito em: 28/06/2011 